\section{(2) OPEN ACCESS}

\title{
Occupational and non-occupational risk factors of sickness absence due to a shoulder lesion
}

\author{
Maria Sirén (1) , ${ }^{1,2}$ Eira Viikari-Juntura, ${ }^{3}$ Jari Arokoski, ${ }^{1,2}$ Svetlana Solovieva ${ }^{3,4}$
}

\begin{abstract}
- Additional material is published online only. To view please visit the journal online (http://dx.doi.org/10.1136/ oemed-2019-106335).

${ }^{1}$ Department of Physical and Rehabilitation Medicine, Helsinki University Hospital, Helsinki, Finland

${ }^{2}$ Faculty of Medicine, University of Helsinki, Helsinki, Finland

${ }^{3}$ Finnish Institute of

Occupational Health, Helsinki, Uusimaa, Finland

${ }^{4}$ National Institute for Health and Welfare, Helsinki, Uusimaa, Finland
\end{abstract}

\section{Correspondence to}

Mrs Maria Sirén, Department of Physical and Rehabilitation Medicine, Helsinki University Hospital, Helsinki 00029, Finland; maria.siren@hus.fi

Received 27 November 2019 Revised 25 February 2020

Accepted 25 February 2020 Published Online First 18 March 2020
ABSTRACT

Objectives To determine the associations of lifestyle factors and cumulative physical workload exposures with sickness absence (SA) due to a shoulder lesion and to calculate their population attributable fractions (PAF). Methods Our nationally representative cohort consisted of 4344 individuals aged 30-62 years who participated in the Finnish Health 2000 Survey. Education, smoking, chronic diseases and work exposures were assessed during interviews and leisure time physical activity with a questionnaire. Weight and height were measured. We followed the individuals for 15 years for the first SA due to a shoulder lesion. We used competing risk regression models. We calculated PAFs to assess the proportion of SA that was attributed to modifiable risk factors.

Results In the entire study population, risk factors of SA were age, daily smoking, being exposed for more than 10 years to physically heavy work and being exposed for more than 10 years to at least two specific physical workload factors. The overall PAF for the modifiable risk factors was $49 \%$. In men, number of specific cumulative exposures, obesity and daily smoking predicted SA with PAF values of $34 \%, 30 \%$ and $14 \%$, respectively. Among women, being exposed for more than 10 years to physically heavy work, number of specific cumulative exposures and daily smoking accounted for $23 \%, 22 \%$ and $15 \%$ of $S A$, respectively.

Conclusions Reducing significantly prolonged exposure to physical workload factors, avoiding regular smoking in both genders and obesity in men has a high potential to prevent SA due to a shoulder lesion.

\section{INTRODUCTION}

Sickness absence (SA) inflicts a major burden on employees, employers and the healthcare system, ${ }^{1}$ which underlines the importance of knowing the modifiable risk factors in order to prevent work disability and retain an active work force. Musculoskeletal diseases are one of the most common workrelated health problems around the world ${ }^{2}$ and have a major impact on SA. ${ }^{3}$ In Finland, shoulder lesions are the second leading cause for SA within musculoskeletal diseases particularly in manual occupations. $^{4}$

Overweight, ${ }^{5}$ smoking, ${ }^{6}$ low physical activity, ${ }^{5} 7$ multimorbidity, ${ }^{8}$ physical workload factors ${ }^{9}$ and low job control ${ }^{1011}$ have been associated with SA due to musculoskeletal diseases. A study focusing on allcause SA found an increased risk for several specific workload factors when exposure time exceeded $25 \%$ of the work time. ${ }^{8}$ Moreover, exposure to a higher number of physical workload factors has

\section{Key messages}

What is already known about this subject?

- Sickness absence (SA) due to shoulder diseases is common.

- Several work-related and lifestyle factors have been linked to SA due to musculoskeletal diseases, but their association on SA due to shoulder diseases is unknown.

What are the new findings?

- We found that the determinants of SA due to a shoulder lesion differed by gender.

- Cumulative exposure to more than two specific physical load factors and daily smoking were, however, associated with SA due to a shoulder lesion in both genders.

How might this impact on policy or clinical practice in the foreseeable future?

- Reducing prolonged exposure to multiple physical workloads has a potential to prevent every fourth case of SA due to a shoulder lesion.

been associated with a higher risk. ${ }^{12} 13$ However, to which extent lifestyle factors and work exposures are related to SA due to a shoulder disease is unknown. Clinically defined rotator cuff lesions have been associated with several physical workload factors, the strongest being composite shoulder load (including posture, force and repetition) ${ }^{12}$ and specifically arm elevation. ${ }^{14-16}$ Of chronic diseases, especially diabetes has been associated with specific shoulder diseases. ${ }^{16} 17$ Weaker associations have been seen for weight-related factors and smoking. ${ }^{17}$ The focus of interest for this paper is to assess the risk factors of SA due to a shoulder lesion in the general population and to estimate to what extent SA due to a shoulder lesion can be reduced by addressing modifiable risk factors.

An explanatory approach to investigate which proportion of absences from work could be prevented by reducing a risk factor is to calculate population attributable fraction (PAF). Previous studies on SA due to any cause have presented noteworthy PAF values for overweight or obesity, ${ }^{18} 19$ smoking ${ }^{18} 19$ and low physical activity. ${ }^{19}$ In a large multicohort study, these three lifestyle factors were reported to explain $30.8 \%$ of SA due to musculoskeletal diseases. ${ }^{5}$ Regarding work-related factors, a Danish study demonstrated that approximately one quarter of all long-term SAs was attributed to lifting 

$\mathrm{N}=8028$ (3637 men and 4391 women)
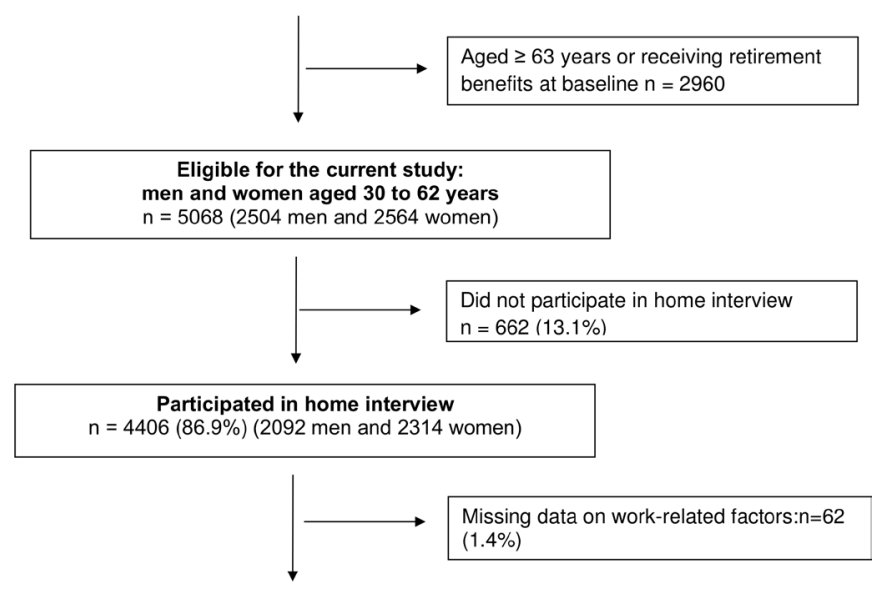

Cohort of the present study
\[ \mathrm{n}=4344 \]
(2051 men and 2293 women)
Record linkage to the register of the Social Insurance
Institute: 243 cases with sickness absence due to a
shoulder lesion until 31.12 .2015
Mean follow-up time 11.6 (range 0 to 15) years.

Figure 1 Flow chart of the formation of the present study sample.

or carrying loads in men and bending or twisting of the neck or back in women. ${ }^{20}$

The aim of this study was to determine the associations of lifestyle factors and cumulative physical work exposures with SA due to a shoulder lesion and to calculate their PAFs.

\section{MATERIAL AND METHODS Study population}

We carried out a population-based study, using a nationally representative random sample of individuals aged 30 years or over who lived in mainland Finland and were alive on 1 July 2000 $(n=8028)$. The sampling and the Health Examination Survey (the Health 2000 Study), which comprised questionnaires, interviews, as well as a health examination, are described in detail elsewhere. ${ }^{21}$ Of the Health 2000 Study population, 5068 individuals aged 30-62 years and belonging to the labour force at baseline comprised our study source population (figure 1). Altogether $86.9 \%$ of the sample $(n=4406)$ participated in home interview. We excluded persons with missing information on work-related factors $(n=62)$. The final study population consisted of 4344 individuals (2051 men and 2293 women), who were followed from the day of their participation in the Health 2000 Study (baseline) to the first SA due to a shoulder lesion, retirement (either disability or old-age retirement), death or end of follow-up (31 December 2015), whichever came first. Date of death was obtained from the Population Information System.

\section{SA due to a shoulder lesion}

The register of the Social Insurance Institution of Finland (SII) provides information on the start and end dates as well as primary diagnoses for all compensated SA spells (full and part time). The first 10 days of full SA are paid by the employer and are not compensated by SII. Full-time SA days are compensated from the 11th day. Part-time SA is possible in Finland after 10 days of full SA and is compensated from the first day. The diagnoses are classified according to the International Statistical Classification of Diseases and Related Health Problems, Tenth Revision (ICD10, Finnish version of ICD classification 1996). The diagnoses of primary interest for this study were M75 (shoulder lesions), excluding M75.0, M75.8 and M75.9.

\section{Potential risk factors}

The Health 2000 Study collected information on sociodemographic factors, ill-health, lifestyle factors and occupational history. Employment and unemployment periods as well as earnings-related pensions were obtained from the Finnish Centre for Pensions (FCP).

Age at baseline was divided into 10-year categories. Height and weight were measured in light indoor clothing during the health examination. Body mass index (BMI) was calculated by dividing weight $(\mathrm{kg})$ with the square of height $\left(\mathrm{m}^{2}\right)$. Overweight and obesity were defined based on BMI using the WHO recommendation of BMI $<25 \mathrm{~kg} / \mathrm{m}^{2}$ (normal), $25-29.9 \mathrm{~kg} / \mathrm{m}^{2}$ (overweight) and $\geq 30 \mathrm{~kg} / \mathrm{m}^{2}$ (obese).

Information about long-term illness was collected during the home interview by a trained nurse (see online supplementary information for the list of 43 diseases). Prevalent chronic disease was defined based on at least one positive response.

Data on the length of education (in years), occupation/occupations, seniority (years in each occupation), physical workload factors in each occupation and smoking were collected during the home interview at baseline. The level of education was defined as: (1) high (>12 years), (2) medium (9-12 years) or (3) low ( $<9$ years). Smoking was assessed with the following questions: (1) 'Have you ever smoked in your life' with two possible responses 'No' and 'Yes'; (2) 'Do you smoke nowadays (cigarettes, cigars or pipe)' with three possible responses 'daily', 'occasionally' and 'not at all'. The subjects were classified as: (1) current daily smokers, if they smoked at the time of interview; (2) not current daily smokers, if they smoked occasionally at the time of interview or never smoked.

Information on the frequency of leisure time physical activity (LTPA) was collected with self-administered questionnaire (Gothenburg scale) $^{22}$ and dichotomised into regular (at least once a week) or irregular.

Psychological distress was assessed at baseline with the Finnish version of the 12 -item GHQ, dichotomising at $4 .^{23}$

The presence of insomnia-related symptoms during preceding 30 days was inquired at baseline with a single question with a scale from 1 (not at all) to 5 (very much). This question was dichotomised with 3 as the cut-off point.

\section{Occupational history and work exposures}

Exposure to the following physical workload factors in each occupation was assessed with the home interview: physically heavy work (work involving, eg, lifting and carrying heavy loads, excavating, shovelling or hammering), manual handling of heavy loads (lifting, carrying or pushing items heavier than $20 \mathrm{~kg}$ at least 10 times per day), working with hands above shoulder level (on average at least 1 hour per day), working in a forward bent posture (on average at least 1 hour per day) and forceful hand movements (involving squeezing, twisting, holding burdens or tools on an average at least 1 hour per day). Cumulative exposure to each physical workload factor was calculated as the total number of years having been exposed during the entire work career. First, we calculated the cumulative exposure to each 
workload factor prior to the baseline using self-reported information on the number of years a person had worked in occupations involving the workload in question. Second, we calculated cumulative exposure during the follow-up using information regarding employment and unemployment periods as well as earnings-related pensions from the FCP to estimate the years a person had worked in the most recent occupation reported at baseline. We assumed that persons did not change their occupation during follow-up. For the analyses, each cumulative exposure was classified into three categories based on the number years being exposed: (1) less than 1 year, (2) 1-10 years and (3) $>10$ years. Third, we calculated the composite cumulative exposure as the number of the four specific workload factors (heavy lifting, working with hands above shoulder level, working in a forward bent posture and forceful hand movements) with the time of exposure $>10$ years. For the analyses, the composite cumulative exposure was categorised into three groups: (0) none, (1) 1 and (2) 2-4 exposures.

Psychosocial exposures were measured with a Finnish version of the Job Content Questionnaire. ${ }^{24}$ Responses were given on a 5 -point Likert scale from 1 (fully agree) to 5 (fully disagree). Psychological job demands scale is the sum of five items. Job control scale is the sum of two subscales: decision authority (three items) and skill discretion (five items). Social support at work was measured with four items. Job demands, job control and social support were dichotomised using gender-specific median cut-off points. Job strain was operationalised using the quadrant approach proposed by Karasek and Theorel12.5 (explained in more detail in online supplementary information). Due to a high number of missing values, psychosocial exposures were used in a subanalysis only.

\section{Statistical analyses}

Competing risk regression models (stcrreg, STATA V.14) were used to examine the associations of possible risk factors with SA due to a shoulder lesion. We accounted for the impact of competing risks (such as retirement and death) on the outcome. Adjusted HRs with 95\% CIs were estimated. First, we estimated the association between each potential risk factor (age, gender, education, BMI, prevalent chronic disease, LTPA, smoking and cumulative physical workload factors) and SA due to a shoulder lesion controlling for age and gender (model 1). Second, we ran model 1 for men and women separately. Third, we carried out an analysis with the fully adjusted model including the following risk factors: age, gender, BMI, prevalent chronic disease, smoking and five cumulative workload factors (model 2). Fourth, we estimated the association of education, BMI, prevalent chronic disease, smoking, cumulative exposure to physically heavy work and composite cumulative exposure with SA due to a shoulder lesion in the total study population controlling for age, gender and all potential risk factors included into the model. Finally, we repeated the last analysis for men and women separately. Because psychological distress and insomnia-related symptoms were assessed for a short recall period at baseline only and can be seen as a consequence of chronic diseases, they were not included in the main analysis and their results are reported in the supplementary tables.

We calculated the PAF to estimate the proportion of SA cases that could be attributed to high BMI, prevalent chronic disease, smoking and cumulative workload factors. For a dichotomous risk factor (eg, smoking), we used the following formula: $P A F=p(R R-1) /(p(R R-1)+1)$, where $p$ denotes the prevalence of the risk factor in the population and RR denotes the relative risk of SA due to a shoulder lesion for the risk factor. For a risk factor with more than two categories (eg, cumulative workload factors), we used the following formula:

$$
P A F=\frac{\sum_{i=1}^{n} p_{i} R R_{i}-1}{\sum_{i=1}^{n} p_{i} R R_{i}}
$$

where $\mathrm{p}_{\mathrm{i}}$ is the proportion of population at exposure level $i$, $\mathrm{RR}_{\mathrm{i}}$ is the relative risk at exposure level $i$ and $n$ is the number of exposure levels.

After the calculation of PAF for each risk factor of interest, we calculated the overall PAF using the sum formula ${ }^{26}: \mathrm{PAF}_{\text {overall }}=1$ $\left(1-\mathrm{PAF}_{1}\right)\left(1-\mathrm{PAF}_{2}\right) \ldots .\left(1-\mathrm{PAF}_{\mathrm{n}}\right)$.

\section{RESULTS}

The prevalence of SA due to a shoulder lesion was $5.2 \%$ in men and $5.9 \%$ in women. The mean baseline age did not differ between those with and without SA in either gender. SA occurred least frequently in persons with a high education (table 1). Obese men were more likely than the others to have SA. Women who were daily smokers or had frequent insomnia-related symptoms had a high prevalence of SA. Those with a clinically defined shoulder disease at baseline had the highest prevalence of SA.

In both genders, the prevalence of SA due to a shoulder lesion was clearly higher among persons who were exposed to physical workload factors for more than 10 years than among those who were not (table 2). The prevalence of SA for persons exposed to these workload factors for more than 10 years was generally higher among women than men and especially seen for heavy physical work, manual handling of heavy loads and work involving forceful hand movements.

Age was associated with SA due to a shoulder lesion with a dose-response pattern (table 3, model 1). Controlling for age and gender, statistically significant predictors of SA included education, BMI, chronic disease, daily smoking and all physical workload exposures. When all potential risk factors except education and LTPA were included simultaneously into the model, statistically significant associations remained for age, daily smoking, cumulative exposure to physically heavy work and forceful hand movements (table 3, model 2). More than 10 years of exposure to heavy physical work and forceful hand movements were independently associated with a 1.66 and 1.74 fold increase in the risk of SA due to a shoulder lesion, respectively. In the fully adjusted model, the risk of SA among men was reduced by $33 \%$ (HR $0.67,95 \% \mathrm{CI} 0.50$ to 0.88 ) compared with women. Insomnia-related symptoms but not psychological distress at baseline were associated with SA due to a shoulder lesion (online supplementary table S1). The inclusion of these two variables into the fully adjusted model (model 2 ) had minor effects on the previously observed associations.

Among men, those with SA were more likely to be exposed to high job demands and had a high strain job more often than those without SA (table 1). In the subanalysis including psychosocial factors, the risk of SA due to a shoulder lesion was increased among persons with high job demands and high job strain. These associations were, however, seen among men only (online supplementary table S2).

In the gender stratified analyses controlling for age, statistically significant predictors of SA in both genders included education, daily smoking and all physical work-load factors (table 3, model 1). In addition, BMI predicted SA due to a shoulder lesion among men and the presence of chronic disease among women. Among men, the highest PAF was seen for cumulative exposure to forceful hand movements (42\%) 
Table 1 Fifteen-year prevalence rate (PR) of SA due to a shoulder lesion according to gender and baseline characteristics ( $n=4344)$

\begin{tabular}{|c|c|c|c|c|c|c|c|c|c|}
\hline & \multicolumn{3}{|c|}{ Men $(n=2051)$} & \multicolumn{3}{|c|}{ Women $(n=2293)$} & \multicolumn{3}{|c|}{ All $(n=4344)$} \\
\hline & $\begin{array}{l}\text { No SA } \\
(n=1944)\end{array}$ & $\begin{array}{l}S A \\
(n=107)\end{array}$ & PR & $\begin{array}{l}\text { No SA } \\
(n=2157)\end{array}$ & $\begin{array}{l}\text { SA } \\
(n=136)\end{array}$ & PR & $\begin{array}{l}\text { No SA } \\
(n=4401)\end{array}$ & $\begin{array}{l}S A \\
(n=243)\end{array}$ & PR \\
\hline & $\mathbf{n}$ & $\mathbf{n}$ & $\%$ & $\mathbf{n}$ & $\mathbf{n}$ & $\%$ & $\mathbf{n}$ & $\mathrm{n}$ & $\%$ \\
\hline \multicolumn{10}{|l|}{ Age group (years } \\
\hline $30-39$ & 667 & 32 & 4.6 & 747 & 38 & 4.8 & 1414 & 12 & 4.7 \\
\hline $40-49$ & 669 & 48 & 6.7 & 736 & 75 & 9.2 & 1405 & 78 & 8.0 \\
\hline $50-62$ & 608 & 27 & 4.3 & 674 & 23 & 3.3 & 1282 & 46 & 3.8 \\
\hline \multicolumn{10}{|l|}{ Education } \\
\hline Low & 263 & 22 & 7.7 & 229 & 12 & 5.0 & 492 & 34 & 6.5 \\
\hline Medium & 862 & 60 & 6.5 & 829 & 78 & 8.6 & 1691 & 138 & 7.5 \\
\hline High & 819 & 25 & 3.0 & 1099 & 46 & 4.0 & 1918 & 71 & 3.6 \\
\hline \multicolumn{10}{|l|}{ BMI $\left(\mathrm{kg} / \mathrm{m}^{2}\right)$} \\
\hline Normal $(<25)$ & 673 & 29 & 4.1 & 1053 & 62 & 5.6 & 1726 & 91 & 5.0 \\
\hline Overweight (25.0-29.9) & 916 & 49 & 5.1 & 686 & 51 & 6.9 & 1602 & 100 & 5.9 \\
\hline Obese $(\geq 30)$ & 355 & 29 & 7.6 & 418 & 23 & 5.2 & 773 & 52 & 6.7 \\
\hline \multicolumn{10}{|l|}{ Chronic disease } \\
\hline No & 1262 & 67 & 5.0 & 1303 & 76 & 5.5 & 2565 & 143 & 5.3 \\
\hline Yes & 681 & 40 & 5.5 & 853 & 60 & 6.6 & 1534 & 100 & 6.1 \\
\hline \multicolumn{10}{|c|}{ Clinically defined shoulder disease* } \\
\hline No & 1774 & 92 & 4.9 & 1992 & 119 & 5.6 & 3766 & 211 & 5.3 \\
\hline Yes & 73 & 9 & 11.0 & 72 & 16 & 18.2 & 145 & 25 & 14.7 \\
\hline \multicolumn{10}{|l|}{ Leisure time physical activity $†$} \\
\hline Little or irregular & 516 & 31 & 5.7 & 422 & 33 & 7.3 & 938 & 64 & 6.4 \\
\hline Regular & 1409 & 75 & 5.1 & 1726 & 102 & 5.6 & 3135 & 177 & 5.3 \\
\hline \multicolumn{10}{|l|}{ Daily smoking } \\
\hline No & 1330 & 66 & 4.7 & 1699 & 86 & 4.8 & 3029 & 152 & 4.8 \\
\hline Yes & 614 & 41 & 6.3 & 457 & 50 & 9.9 & 1071 & 91 & 7.8 \\
\hline \multicolumn{10}{|l|}{ Job demandsł } \\
\hline Low & 774 & 33 & 4.1 & 836 & 55 & 6.2 & 1610 & 88 & 5.2 \\
\hline High & 910 & 66 & 6.8 & 934 & 64 & 6.4 & 1844 & 130 & 6.6 \\
\hline \multicolumn{10}{|l|}{ Job control§ } \\
\hline Low & 868 & 55 & 6.0 & 738 & 59 & 7.4 & 1606 & 114 & 6.6 \\
\hline High & 833 & 45 & 5.1 & 1035 & 60 & 5.5 & 1868 & 105 & 5.3 \\
\hline \multicolumn{10}{|l|}{ Social supportๆ } \\
\hline Low & 604 & 35 & 5.5 & 553 & 39 & 6.6 & 1157 & 74 & 6.0 \\
\hline High & 1073 & 66 & 5.8 & 1218 & 83 & 6.4 & 2291 & 149 & 6.1 \\
\hline \multicolumn{10}{|l|}{ Job strain** } \\
\hline Low strain job & 367 & 13 & 3.4 & 458 & 24 & 5.0 & 825 & 37 & 4.3 \\
\hline Passive job & 404 & 20 & 4.7 & 364 & 30 & 7.6 & 768 & 50 & 6.1 \\
\hline Active job & 466 & 30 & 6.0 & 558 & 35 & 5.9 & 1024 & 65 & 6.0 \\
\hline High strain job & 451 & 35 & 7.2 & 366 & 25 & 6.4 & 817 & 60 & 6.8 \\
\hline \multicolumn{10}{|l|}{ Psychological distresst† } \\
\hline No or mild $(1-3)$ & 1585 & 87 & 5.2 & 1719 & 105 & 5.8 & 3304 & 192 & 5.5 \\
\hline At least moderate (4-12) & 289 & 16 & 5.2 & 384 & 30 & 7.2 & 673 & 46 & 6.4 \\
\hline \multicolumn{10}{|l|}{ Insomnia-related symptomsł‡ } \\
\hline No or rare & 1374 & 69 & 4.8 & 1448 & 81 & 5.3 & 2822 & 150 & 5.0 \\
\hline Occasional & 345 & 26 & 7.0 & 442 & 29 & 6.2 & 787 & 55 & 6.5 \\
\hline Frequent & 156 & & 4.9 & 216 & 25 & 10.4 & 372 & 33 & 8.1 \\
\hline
\end{tabular}

The mean age of men with no SA was 44.27 (95\% Cl 43.89 to 44.65$)$ and with SA 44.20 (95\% Cl 43.90 to 45.55$)$.

The mean age of women with no SA was 44.27 (95\% Cl 43.90 to 44.63 ) and with SA 43.63 (95\% Cl 42.51 to 44.74$)$.

*Data available for 1948 men and 2199 women.

tData available 2031 men and 2283 women.

‡Dataavailable for 1783 men and 1889 women.

§Data available for 1801 men and 1892 women.

IData availablefor 1778 men and 1893 women.

**Data available for 1776 men and 1861 women

††Data available for 1977 men and 2238 women.

¥‡Data available for 1978 men and 2241 women.

BMI, body mass index; SA, sickness absence. 
Table 2 Fifteen-yearyear prevalence rate (PR) of SA due to a shoulder lesion according to gender and cumulative exposure to physical workload factors

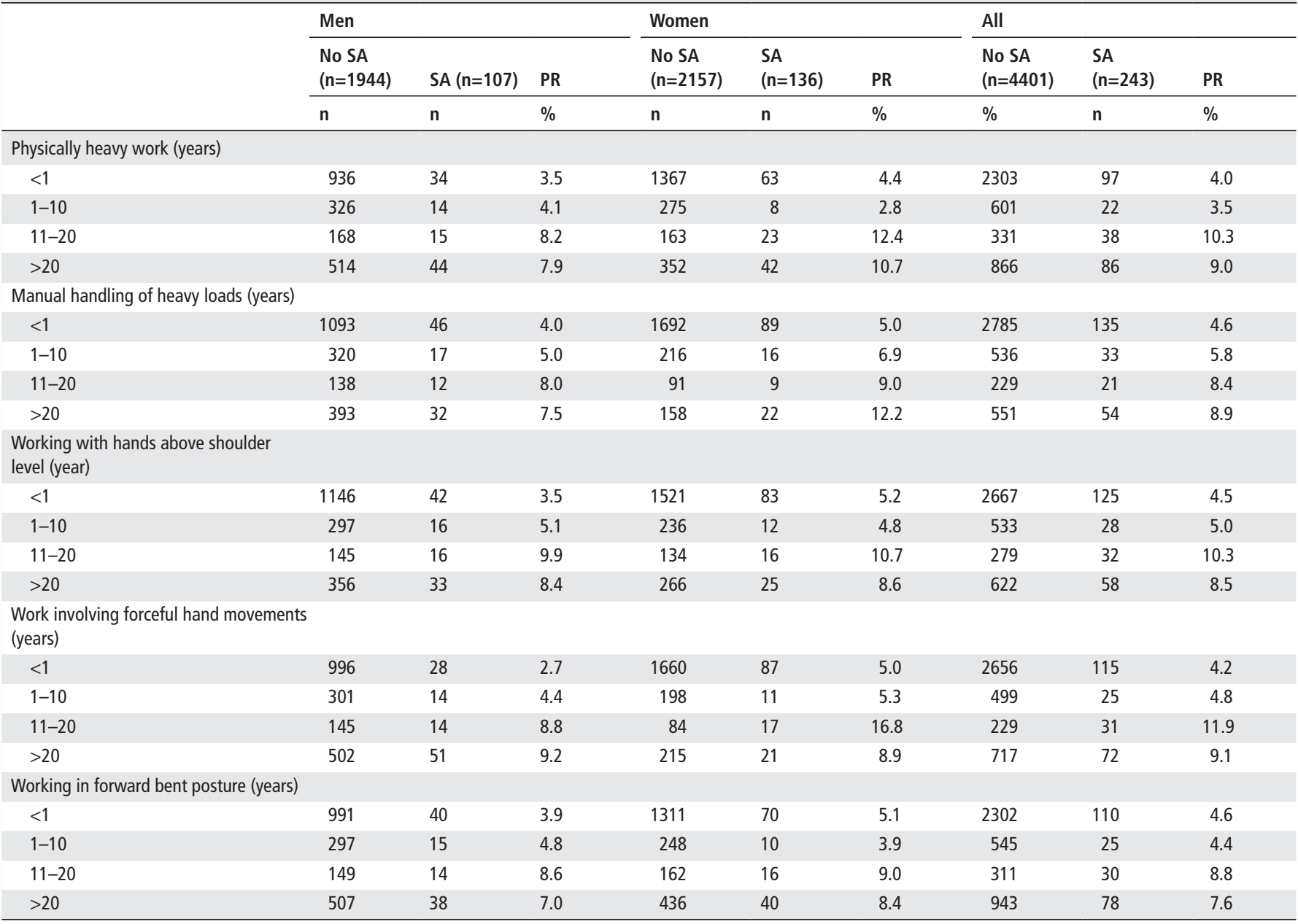

SA, sickness absence.

followed by obesity (28\%). Among women, all PAF values were lower, the highest being for cumulative exposure to physically heavy work $(28 \%)$.

In the fully adjusted model including the composite cumulative exposure variable for specific physical exposures, the overall PAF for SA was 49\% (table 4). This value was higher for men $(60 \%)$ than women $(49 \%)$. Of individual risk factors among men, the highest PAF was observed for composite cumulative workload (34\%) followed by obesity (30\%). Among women, all work-related factors and daily smoking were statistically significant predictors of SA, with PAF values of $22 \%, 23 \%$ and $15 \%$ for composite cumulative workload, cumulative exposure to heavy physical work and daily smoking, respectively. Further inclusion of psychological distress and insomnia-related symptoms into the fully adjusted model led to an increase in the overall PAF values (online supplementary table S3).

Inclusion of job demands into the final model did not change the observed associations for the other variables in the entire study population (online supplementary table S4). In the gender stratified analysis, inclusion of job demands resulted in an increase in the overall PAF value in both men and women $(68 \%$ and $60 \%$, respectively). Job demands was statistically significantly associated with SA due to a shoulder lesion among men only with a PAF value of $23 \%$.

\section{DISCUSSION}

This paper is to our knowledge the first to examine the relative contribution of lifestyle factors and cumulative physical workload exposures to SA due to a shoulder lesion and to estimate the proportion of SAs that could be avoided by targeting these factors. We found that in the entire study population the risk factors of SA were age, daily smoking, being exposed for more than 10 years to physically heavy work and being exposed for more than 10 years to at least two specific physical workload factors. The overall PAF for the three modifiable risk factors was $49 \%$. The determinants of SA differed by gender, however. Obesity predicted SA due to a shoulder lesion among men only with a PAF value of $30 \%$. Among women, being exposed for more than 10 years to physically heavy work or to any specific physical load exposure accounted for $23 \%$ and $24 \%$ of SA, respectively. Accounting for job demands did not affect the observed associations and showed an association with SA due to a shoulder lesion in men only. In total, the significant modifiable risk factors explained $60 \%$ and $49 \%$ of SA due to a shoulder lesion in men and women, respectively.

We also found that in addition to cumulative exposure to heavy physical work, among the specific cumulative exposures, work involving forceful hand movements contributed the most to SA due to a shoulder lesion. Due to the absence of other studies on SA due to shoulder disorders, the comparability of 
Table 3 Associations between potential risk factors (PAFs) and sickness absence due to a shoulder lesion

\begin{tabular}{|c|c|c|c|c|c|c|c|c|c|c|c|c|}
\hline & & Model & & & & & & & & & Mode & \\
\hline & & All & & & Men & & & Wome & & & All & \\
\hline & & $\mathrm{HR}^{*}$ & $95 \% \mathrm{Cl}$ & PAF & HRt & $95 \% \mathrm{Cl}$ & PAF & HRt & $95 \% \mathrm{Cl}$ & PAF & HR & $95 \% \mathrm{Cl}$ \\
\hline $\begin{array}{l}\text { Age (at base } \\
\text { (years) }\end{array}$ & & & & & & & & & & & & \\
\hline & $30-39$ & 1 & & & 1 & & & 1 & & & 1 & \\
\hline & $40-49$ & $2.29 \S$ & 1.71 to 3.08 & & 2.02 & 1.29 to 3.16 & & 2.5 & 1.69 to 3.69 & & 2.12 & 1.57 to 2.86 \\
\hline & $50-62$ & 4.57 & 3.02 to 6.91 & & 5.35 & 2.98 to 9.60 & & 3.82 & 2.12 to 6.86 & & 4 & 2.62 to 6.12 \\
\hline Gender & & & & & & & & & & & & \\
\hline & Men & $0.33 \dagger$ & 0.72 to 1.19 & & NA & & & NA & & & 0.67 & 0.50 to 0.88 \\
\hline & Women & 1 & & & NA & & & NA & & & 1 & \\
\hline Education & & & & & & & & & & & & \\
\hline & Low & 3.07 & 2.00 to 4.73 & & 4.38 & 2.38 to 8.08 & & 2.06 & 1.07 to 3.98 & & - & to \\
\hline & Middle & 2.57 & 1.92 to 3.43 & & 2.48 & 1.56 to 3.97 & & 2.65 & 1.83 to 3.84 & & - & to \\
\hline & High & 1 & & & 1 & & & 1 & & & - & \\
\hline BMI $\left(\mathrm{kg} / \mathrm{m}^{2}\right)$ & & & & 0.19 & & & & & & & & \\
\hline & Normal $(<25)$ & 1 & & & 1 & & & 1 & & & 1 & \\
\hline & Overweight (25.0-29.9) & 1.36 & 1.02 to 1.82 & & 1.38 & 0.87 to 2.19 & & 1.44 & 0.99 to 2.08 & & 1.24 & 0.93 to 1.65 \\
\hline & Obese $(\geq 30)$ & 1.49 & 1.05 to 2.10 & & 2.1 & 1.25 to 3.54 & 0.28 & 1.09 & 0.67 to 1.76 & & 1.34 & 0.95 to 1.90 \\
\hline Chronic dise & & & & & & & & & & & & \\
\hline & No & 1 & & & 1 & & & 1 & & & & \\
\hline & Yes & 1.41 & 1.09 to 1.83 & 0.13 & 1.26 & 0.85 to 1.88 & & 1.52 & 1.08 to 2.14 & 0.17 & 1.27 & 0.98 to 1.65 \\
\hline Leisure time & cal activity & & & & & & & & & & & \\
\hline & Little or irregular & 1 & & & 1 & & & 1 & & & - & \\
\hline & Regular & 0.79 & 0.59 to 1.06 & & 0.92 & 0.60 to 1.40 & & 0.69 & 0.47 to 1.03 & & - & to \\
\hline Daily smokin & & & & & & & & & & & & \\
\hline & No & 1 & & & 1 & & & 1 & & & 1 & \\
\hline & Yes & 1.8 & 1.39 to 2.34 & 0.18 & 1.58 & 1.07 to 2.33 & 0.16 & 1.99 & 1.40 to 2.82 & 0.18 & 1.7 & 1.30 to 2.21 \\
\hline $\begin{array}{l}\text { Cumulative } \\
\text { (years) }\end{array}$ & Ire to physically heavy w & & & & & & & & & & & \\
\hline & $<1$ & 1 & & & 1 & & & 1 & & & 1 & \\
\hline & $1-10$ & 0.97 & 0.61 to 1.54 & & 1.24 & 0.67 to 2.32 & & 0.69 & 0.33 to 1.45 & & 0.73 & 0.42 to 1.29 \\
\hline & $>10$ & 2.66 & 2.03 to 3.49 & 0.27 & 2.33 & 1.53 to 3.55 & 0.24 & 2.99 & 2.11 to 4.23 & 0.28 & 1.91 & 1.14 to 3.21 \\
\hline $\begin{array}{l}\text { Cumulative } \\
\text { heavy loads }\end{array}$ & Ire to manual handling of & & & & & & & & & & & \\
\hline & $<1$ & 1 & & & 1 & & & 1 & & & 1 & \\
\hline & $1-10$ & 1.38 & 0.94 to 2.03 & & 1.34 & 0.77 to 2.34 & & 1.41 & 0.83 to 2.40 & & 1.23 & 0.76 to 2.00 \\
\hline & $>10$ & 2.18 & 1.63 to 2.92 & 0.09 & 1.99 & 1.31 to 3.01 & 0.1 & 2.4 & 1.59 to 3.63 & 0.07 & 0.8 & 0.45 to 1.41 \\
\hline $\begin{array}{l}\text { Cumulative } \\
\text { shoulder lev }\end{array}$ & $\begin{array}{l}\text { Ire to work with hands al } \\
\text { rs) }\end{array}$ & & & & & & & & & & & \\
\hline & $<1$ & 1 & & & 1 & & & 1 & & & 1 & \\
\hline & $1-10$ & 1.13 & 0.75 to 1.71 & & 1.45 & 0.81 to 2.58 & & 0.94 & 0.51 to 1.72 & & 0.86 & 0.53 to 1.40 \\
\hline & $>10$ & 2.26 & 1.72 to 2.98 & 0.14 & 2.74 & 1.81 to 4.14 & 0.24 & 1.93 & 1.33 to 2.82 & 0.07 & 1.34 & 0.83 to 2.18 \\
\hline $\begin{array}{l}\text { Cumulative } \\
\text { movements }\end{array}$ & Ire to forceful hand & & & & & & & & & & & \\
\hline & $<1$ & 1 & & & 1 & & & 1 & & & 1 & \\
\hline & $1-10$ & 1.34 & 0.87 to 2.08 & & 1.72 & 0.90 to 3.26 & & 1.15 & 0.61 to 2.15 & & 1.39 & 0.78 to 2.47 \\
\hline & $>10$ & 2.98 & 2.25 to 3.94 & 0.26 & 3.51 & 2.25 to 5.47 & 0.42 & 2.7 & 1.83 to 3.96 & 0.14 & 2.32 & 1.32 to 4.07 \\
\hline $\begin{array}{l}\text { Cumulative } \\
\text { (years) }\end{array}$ & Ire to forward bent postu & & & & & & & & & & & \\
\hline & $<1$ & 1 & & & 1 & & & 1 & & & 1 & \\
\hline & $1-10$ & 1.07 & 0.69 to 1.66 & & 1.31 & 0.72 to 2.37 & & 0.89 & 0.46 to 1.73 & & 0.96 & 0.57 to 1.63 \\
\hline & $>10$ & 1.93 & 1.48 to 2.52 & 0.14 & 2.12 & 1.40 to 3.20 & 0.19 & 1.81 & 1.27 to 2.57 & 0.11 & 1.03 & 0.61 to 1.73 \\
\hline
\end{tabular}

Adjusted HRs with $95 \% \mathrm{Cls}$ and PAFs.

The bolded values are statistically significant.

${ }^{*}$ HRs are adjusted for age and gender.

tHRs are adjusted for age.

‡HRs are adjusted for all variables in the table, except education and leisure time physical activity.

$\S$ HRs are adjusted for gender.

BMI, body mass index. 
Table 4 Associations between potential risk factors (PAFs) and sickness absence due to a shoulder lesion

\begin{tabular}{|c|c|c|c|c|c|c|c|c|c|c|}
\hline & \multicolumn{3}{|l|}{ All } & \multicolumn{3}{|l|}{ Men } & \multicolumn{3}{|c|}{ Women } \\
\hline & & $H R^{*}$ & $95 \% \mathrm{Cl}$ & PAF & HRt & $95 \% \mathrm{Cl}$ & PAF & HRt & $95 \% \mathrm{Cl}$ & PAF \\
\hline \multicolumn{11}{|c|}{ Age (at baseline) (years) } \\
\hline & $30-39$ & 1.00 & & & 1.00 & & & 1.00 & & \\
\hline & $40-49$ & 2.10 & 1.56 to 2.83 & & 1.99 & 1.27 to 3.13 & & 2.23 & 1.50 to 3.31 & \\
\hline & $50-62$ & 3.85 & 2.53 to 5.85 & & 4.78 & 2.63 to 8.69 & & 3.07 & 1.69 to 5.57 & \\
\hline \multicolumn{11}{|l|}{ BMI $\left(\mathrm{kg} / \mathrm{m}^{2}\right)$} \\
\hline & Normal $(<25)$ & 1.00 & & & 1.00 & & & 1.00 & & \\
\hline & Overweight (25.0-29.9) & 1.30 & 0.97 to 1.73 & & 1.43 & 0.90 to 2.28 & & 1.28 & 0.88 to 1.86 & \\
\hline & Obese $(\geq 30)$ & 1.36 & 0.96 to 1.93 & & 2.18 & 1.29 to 3.68 & 0.30 & 0.91 & 0.56 to 1.48 & \\
\hline \multicolumn{11}{|l|}{ Chronic disease } \\
\hline & No & 1.00 & & & 1.00 & & & 1.00 & & \\
\hline & Yes & 1.28 & 0.98 to 1.66 & & 1.13 & 0.75 to 1.69 & & 1.40 & 0.99 to 1.97 & \\
\hline \multirow[t]{3}{*}{ Daily smoking } & & & & 0.16 & & & 0.14 & & & 0.15 \\
\hline & No & 1.00 & & & 1.00 & & & 1.00 & & \\
\hline & Yes & 1.69 & 1.30 to 2.19 & & 1.51 & 1.02 to 2.24 & & 1.81 & 1.28 to 2.58 & \\
\hline \multicolumn{2}{|c|}{ Cumulative exposure to physically heavy work (years) } & & & 0.18 & 0.19 & & & & & 0.23 \\
\hline & $<10$ & 1.00 & & & 1.00 & & & 1.00 & & \\
\hline & $>10$ & 1.73 & 1.26 to 2.38 & & 1.23 & 0.75 to 2.03 & & 2.16 & 1.43 to 3.25 & \\
\hline \multicolumn{2}{|c|}{ Number of exposers with time of exposure $>10$ years } & & & 0.26 & 0.31 & & & & & 0.22 \\
\hline & None & 1.00 & & & 1.00 & & & 1.00 & & \\
\hline & One & 1.28 & 0.86 to 1.91 & & 0.64 & 0.26 to 1.56 & & 1.59 & 0.99 to 2.54 & \\
\hline & Two to four & 2.04 & 1.43 to 2.91 & & 2.50 & 1.45 to 4.30 & 0.34 & 1.82 & 1.13 to 2.93 & \\
\hline Overall PAF & & & & 0.49 & & & 0.60 & & & 0.49 \\
\hline
\end{tabular}

HRs and their $95 \% \mathrm{Cl}$ are adjusted.

Adjusted $\mathrm{HRs}$ with $95 \% \mathrm{Cl}$ and PAFs.

Adjusted HRs with $95 \% \mathrm{Cls}$ and PAFs.

The bolded values are statistically significant.

${ }^{*}$ For gender and all variables in the table.

tFor all variables in the table.

$\mathrm{BMI}$, body mass index.

our results is limited. Our findings are in line with previous research on the role of specific workload exposures in shoulder diseases, showing an association of working with hands above shoulder level and heavy lifting with chronic rotator cuff tendinitis. ${ }^{15}$ In a Danish case-control study, exposure to arm elevation for more than 10 years increased the odds of surgery for supraspinatus impingement syndrome by 2.3 and 1.9 times and exposure to forceful shoulder exertions for more than 10 years by 2.5 and 2.0 times, in men and women, respectively. ${ }^{27}$ There are no pathomechanical studies on the effects of cumulative load on rotator cuff tendons, but the prevailing view is that the overload of tendons induces reactive tendinopathy, which in turn leads to tendon disrepair and eventually with prolonged overload to degenerative tendinopathy. ${ }^{28}$

Several reports have shown that women have a higher risk of SA than men, ${ }^{29-32}$ and this was also observed in the present study. However, the overall contribution of the risk factors was lower among women than men, suggesting that women have some underlying risk factors of SA that this study did not take into consideration. It has been found that work-to-family interference especially in women, who bear the main responsibility for housework and family, is associated with long-term SA. ${ }^{33}$

Obesity explained $30 \%$ of the SA in men in our study. Obesity is known to induce tendon damage in a multifactorial way. ${ }^{34}$ Obesity and overweight have been reported to be independent risk factors for shoulder impingement syndrome surgery in both genders. ${ }^{27}$ In addition, $8.9 \%$ and $7.8 \%$ of SA due to musculoskeletal diseases have been found to be attributed to overweight and obesity, respectively. ${ }^{5}$
Epidemiological evidence for the associations between smoking and shoulder pain or disorders is inconsistent. ${ }^{175}$ In a meta-analysis pooling data from four occupational cohorts, smoking was associated with SA due to musculoskeletal diseases with a PAF value of $6.3 \% .^{5}$ Moreover, an analysis among Dutch farmers found that $21 \%$ of the SA due to a musculoskeletal disease could be prevented in the absence of smoking. ${ }^{36}$ In our study, daily smoking was associated with SA due to a shoulder lesion in the entire population with a PAF value of $16 \%$. The hypothesis that smoking increases a person's risk for a rotator cuff disease is biologically plausible. Nicotine decreases oxygen delivery to tissues by vasoconstriction ${ }^{37}$ and carbon monoxide decreases the partial pressure of oxygen that is necessary for cellular metabolism. ${ }^{38}$ These intrinsic changes probably enhance tendon degeneration and may eventually lead to a symptomatic shoulder problem. Smoking may also be related to other factors leading to SA.

Our results of showing no association between the frequency of LTPA and SA due to a shoulder lesion are in line with previous results. ${ }^{1539}$ There is some information for an association between shoulder pain and specific types of exercise that may be injurious for the shoulder. ${ }^{39}$ Unfortunately, we did not have information of the types of physical exercise in our study.

\section{Strengths and limitations}

The study population is a random sample of Finns aged 30 years or older, and the participation rate was high. This allowed us to estimate the proportion of SA that could be prevented 
by targeting modifiable risk factors. SAs were taken from the register of SII, covering all SAs lasting more than 10 days in Finland and allowing complete follow-up of all individuals. We took into consideration lifetime occupational history and addressed several work exposures that are known to be linked to rotator cuff diseases. Weight and height were measured by trained nurses. We used a standardised questionnaire and trained interviewers.

Nonetheless, using an interview at baseline to collect retrospectively information on occupational exposures is prone to recall bias. ${ }^{40}$ The outcome, however, was measured prospectively; therefore, a differential bias is unlikely. Additional limitations to this study include the assessment of psychosocial factors at baseline only. Moreover, due to many missing values psychosocial factors were included in a subanalysis only. Other limitations include self-reported measurements of smoking and physical activity. Further research should also be undertaken to investigate the association between specific chronic diseases and SA due to a shoulder lesion. In this paper, the size of the study population compelled us to analyse all chronic diseases as one group.

In conclusion, our findings suggest that significantly reducing prolonged exposure to physical workload factors, avoiding regular smoking in both genders and obesity in men has a high potential to prevent SA due to a shoulder lesion.

Contributors All authors planned the study. SS made the analyses. MS drafted the manuscript. All authors critically reviewed and approved the manuscript.

Funding This study was funded by NordForsk (grant number 76659), the Finnish Work Environment Fund (grant number 115105), the Academy of Finland (grant number 303534), the Nordic Council of Ministers (grant number 101250) and by a university-level health research (Helsinki University Hospital/Internal Medicine and Rehabilitation) project (Y101500007) (grant number HUS/174/2019).

Competing interests None declared.

Patient consent for publication Not required.

Ethics approval The Section for Epidemiology and Public Health of the Ethics Committee of the Hospital District of Helsinki and Uusimaa approved the study design of the Health 2000 Study 31 May 2000. Participation in the study was voluntary, and the subjects were asked to sign an informed consent form. The consent contained a permission for using their data in studies on health, various diseases and their determinants, including linkage to the registers.

Provenance and peer review Not commissioned; externally peer reviewed.

Data availability statement Data may be obtained from a third party and are not publicly available. National Institute of Health and Welfare holds the data on the Health 2000 cohort. These data can be obtained by a research proposal. The data on sickness absences can be obtained from The Social Insurance Institution of Finland by applying for access to information for research purposes.

Open access This is an open access article distributed in accordance with the Creative Commons Attribution Non Commercial (CC BY-NC 4.0) license, which permits others to distribute, remix, adapt, build upon this work non-commercially, and license their derivative works on different terms, provided the original work is properly cited, appropriate credit is given, any changes made indicated, and the use is non-commercial. See: http://creativecommons.org/licenses/by-nc/4.0/.

ORCID iD

Maria Sirén http://orcid.org/0000-0002-9533-8543

\section{REFERENCES}

1 Henderson M, Glozier N, Holland Elliott K. Long term sickness absence. BMJ 2005;330:802-3.

2 The prevention of occupational diseases, Geneva: international labour organization 2013

3 Osh in figures: work-related musculoskeletal disorders in the EU - facts and figures, Luxembourg: European agency for safety and health at work 2010.

4 Pekkala J, Rahkonen 0 , Pietiläinen 0 , et al. Sickness absence due to different musculoskeletal diagnoses by occupational class: a register-based study among 1.2 million Finnish employees. Occup Environ Med 2018;75:296-302.
5 Virtanen M, Ervasti J, Head J, et al. Lifestyle factors and risk of sickness absence from work: a multicohort study. Lancet Public Health 2018;3:e545-54.

6 Hallman DM, Holtermann A, Björklund M, et al. Sick leave due to musculoskeletal pain: determinants of distinct trajectories over 1 year. Int Arch Occup Environ Health 2019;92:1099-108.

7 Holstila A, Mänty M, Rahkonen O, et al. Changes in leisure-time physical activity and physical and mental health functioning: a follow-up study. Scand J Med Sci Sports 2017;27:1785-92.

8 Ubalde-Lopez M, Delclos GL, Benavides FG, et al. The effect of multimorbidity on sickness absence by specific diagnoses. Occup Med 2017;67:93-100.

9 Sommer TG, Svendsen SW, Frost P. Sickness absence and permanent work disability in relation to upper- and lower-body pain and occupational mechanical and psychosocia exposures. Scand J Work Environ Health 2016;42:481-9.

10 Foss L, Gravseth HM, Kristensen P, et al. The impact of workplace risk factors on longterm musculoskeletal sickness absence: a registry-based 5 -year follow-up from the Oslo health study. J Occup Environ Med 2011;53:1478-82.

11 Janssens H, Clays E, De Clercq B, et al. The relation between psychosocial risk factors and cause-specific long-term sickness absence. Eur J Public Health 2014;24:428-33.

12 Andersen LL, Fallentin N, Thorsen SV, et al. Physical workload and risk of longterm sickness absence in the general working population and among blue-collar workers: prospective cohort study with register follow-up. Occup Environ Med 2016;73:246-53.

13 Labriola M, Lund T, Burr H. Prospective study of physical and psychosocial risk factors for sickness absence. Occup Med 2006;56:469-74.

14 van der Molen HF, Foresti C, Daams JG, et al. Work-Related risk factors for specific shoulder disorders: a systematic review and meta-analysis. Occup Environ Med 2017;74:745-55

15 Miranda H, Viikari-Juntura E, Heistaro S, et al. A population study on differences in the determinants of a specific shoulder disorder versus nonspecific shoulder pain without clinical findings. Am J Epidemiol 2005;161:847-55.

16 Leong HT, Fu SC, He X, et al. Risk factors for rotator cuff tendinopathy: a systematic review and meta-analysis. J Rehabil Med 2019;51:627-37.

17 Viikari-Juntura E, Shiri R, Solovieva S, et al. Risk factors of atherosclerosis and shoulder pain--is there an association? A systematic review. Eur J Pain 2008:12:412-26

18 Laaksonen M, Piha K, Martikainen P, et al. Health-Related behaviours and sickness absence from work. Occup Environ Med 2009:66:840-7.

19 Robroek SJW, van den Berg TIJ, Plat JF, et al. The role of obesity and lifestyle behaviours in a productive workforce. Occup Environ Med 2011:68:134-9.

20 Bang Christensen K, Lund T, Labriola M, et al. The fraction of long-term sickness absence attributable to work environmental factors: prospective results from the Danish work environment cohort study. Occup Environ Med 2007;64:487-9.

21 Heistaro S. Methodology Report Health 2000 Survey Publications of the National Public Health Institute., Helsinki KTL-National Public Health Institute, Department of Health and Functional Capacity 2008.

22 Wilhelmsen L, Tibblin G, Werkö L. A primary preventive study of Gothenburg, Sweden. Prev Med 1972;1:153-60.

23 Goldberg D. The detection of psychiatric illness by questionnaire. Oxford University Press: Oxford, 1972

24 Karasek R, Brisson C, Kawakami N, et al. The job content questionnaire (JCQ): an instrument for internationally comparative assessments of psychosocial job characteristics. J Occup Health Psychol 1998;3:322-55.

25 Karasek RA, Theorell T, Stress Healthy Work:. Productivity, and the Reconstruction of Working Life. New York: Basic Books, 1990.

26 Miettinen OS. Proportion of disease caused or prevented by a given exposure, trait or intervention. Am J Epidemiol 1974;99:325-32.

27 Dalbøge A, Frost P, Andersen JH, et al. Surgery for subacromial impingement syndrome in relation to intensities of occupational mechanical exposures across 10-year exposure time windows. Occup Environ Med 2018;75:176-82.

28 Cook JL, Purdam CR. Is tendon pathology a continuum? A pathology model to explain the clinical presentation of load-induced tendinopathy. Br I Sports Med 2009:43:409-16.

29 Laaksonen M, Mastekaasa A, Martikainen P, et al. Gender differences in sickness absence--the contribution of occupation and workplace. Scand I Work Environ Health 2010;36:394-403.

30 Smeby L, Bruusgaard D, Claussen B. Sickness absence: could gender divide be explained by occupation, income, mental distress and health? Scand I Public Health 2009:37:674-81.

31 Allebeck P, Mastekaasa A. Swedish Council on Technology Assessment in Health Care (SBU). Chapter 5. Risk factors for sick leave - general studies. Scand I Public Health Supp/ 2004;63:49-108.

32 Labriola M, Holte KA, Christensen KB, et al. The Attribution of work environment in explaining gender differences in long-term sickness absence: results from the prospective DREAM study. Occup Environ Med 2011;68:703-5.

33 Lidwall U, Marklund S, Voss M. Work-family interference and long-term sickness absence: a longitudinal cohort study. Eur J Public Health 2010;20:676-81.

34 Abate M, Salini V. Andia I. How obesity affects tendons? Adv Exp Med Biol 2016;920:167-77. 
35 Rechardt M, Shiri R, Karppinen J, et al. Lifestyle and metabolic factors in relation to shoulder pain and rotator cuff tendinitis: a population-based study. BMC Musculoskelet Disord 2010;11:165.

36 Hartman E, Oude Vrielink HHE, Huirne RBM, et al. Risk factors for sick leave due to musculoskeletal disorders among self-employed Dutch farmers: a case-control study. Am J Ind Med 2006;49:204-14.

37 Mosely LH, Finseth F. Cigarette smoking: impairment of digital blood flow and wound healing in the hand. Hand 1977:9:97-101.
38 Leow YH, Maibach HI. Cigarette smoking, cutaneous vasculature, and tissue oxygen Clin Dermatol 1998;16:579-84.

39 Miranda H, Viikari--Juntura E, Martikainen R, et al. Physical exercise and musculoskeletal pain among forest industry workers. Scand I Med Sci Sports 2001;11:239-46.

40 Wiktorin C, Karlqvist L, Winkel J. Validity of self-reported exposures to work postures and manual materials handling. Stockholm music I study Group. Scand I Work Environ Health 1993;19:208-14. 